'Universidade de São Paulo (USP), Faculdade de Medicina (FM), Hospital das Clínicas, São Paulo, SP, Brasil

2Universidade de São Paulo (USP), Faculdade de Medicina (FM), Instituto do Câncer do Estado de São Paulo (ICESP), São Paulo, SP, Brasil

Financial support: None. Conflicts of interest: No conflicts of interest declared concerning the publication of this article. Submitted: June 252019. Accepted: September 15, 2019.

Study carried out at Instituto de Câncer do Estado de São Paulo - ICESP, Faculdade de Medicina (FM), Universidade de São Paulo (USP), São Paulo, SP, Brasil

This study was presented at the XVII Congresso Brasileiro de Cirurgia de Cabeça e Pescoço 2019.

\section{Recurrence of laryngeal squamous cell carcinoma in patients undergoing organ preservation therapy: are there symptoms associated with recurrence?}

\author{
Sonyara Rauedys Lisboa ${ }^{1 *}$, Daniel Abreu Rocha ${ }^{1}$, \\ Richard Godoy Mejia ${ }^{1}$, Adolfo Cotarelli Sasaki', \\ Matheus Gerhard Rosenfeld ${ }^{1}$, Leandro Luongo de Matos ${ }^{2}$, Daniel Marin Ramos², \\ Marco Aurélio Vamondes Kulcsar ${ }^{2}$
}

\begin{abstract}
Introduction: The larynx is a organ of the upper aerodigestive tract that plays an essential role in protecting the airways during swallowing. Squamous cell carcinoma is the most common malignant neoplasm affecting this region and early diagnosis has an important role in treatment outcome. Objectives: This study aims to evaluate whether patients with hypopharyngeal and/or laryngeal squamous cell carcinoma (SCC) who underwent organ preservation therapy (OPT) present at the time of relapse some factor that determines the local recurrence of the disease. Methods: Patients submitted to OPT were selected at the Cancer Institute of the State of São Paulo (ICESP), at the end of treatment, from January 2012 to December 2017. We collected retrospective data on demographics, clinical staging, location of the primary tumor, presence or absence of recurrence, weight and percentage of weight loss at different moments, alimentary pathway and symptomatology at the time of relapse. Results: The absence of symptoms was associated with the absence of relapse $(p<0.001)$. Fully oral diet at the last visit was a significant factor for the absence of relapse $(p=0.005)$. The weight comparison of all the patients before the beginning of OPT and after the end of the treatment, showed an average drop of $3.4 \mathrm{~kg}$. In the group-separated analysis, patients who did not recur showed an average loss of $0.7 \%$. Patients with relapse, showed a loss of $2.0 \%$ of the weight at the time of relapse. Conclusion: Weight loss and the presence of symptoms were important predictors of recurrence with statistical significance. These factors may help to better manage these patients, with earlier investigations and, therefore, the possibility of rescue treatments with a shorter duration.
\end{abstract}

Keywords: laryngeal neoplasms; larynx; hypopharyngeal neoplasm.

\section{Introduction}

The larynx and laryngopharynx are organs of the upper aerodigestive tract that extend from the oropharynx, at the superior border, to the esophagus and trachea, at the inferior. Divided into subunits (supraglottis, glottis and 
infraglottis), the larynx presents different lymphatic drainage patterns and, together with the laryngopharynx, plays an essential role in protecting the airways during swallowing 1 . Squamous cell carcinoma is the most common malignant neoplasm affecting these regions. Location in the laryngopharynx is less common, with incidence varying between $5-8 \%{ }^{2}$. The larynx is the second most common location of head and neck squamous cell carcinoma ${ }^{3}$. An increased incidence was observed in both men and women in developing countries, in contrast with the situation in developed countries ${ }^{2}$. These carcinomas have common risk factors, including excessive tobacco and alcohol consumption.

The laryngopharynx neoplasm presents one of the worst survival rates among head and neck neoplasms, with only $30-35 \%$ within five years ${ }^{4}$. Recurrence is common, with around 50\% relapse in the first year after diagnosis ${ }^{4}$.

Despite recent advances in chemotherapy, radiotherapy and reconstruction surgery, there is still no preferential treatment for laryngopharyngeal neoplasms ${ }^{5}$. There is currently, however, a global trend toward therapeutic strategies aiming at organ preservation. Laryngeal neoplasm therapies are based on three main alternatives: total laryngectomy, partial laryngectomies and radiotherapy associated or not with systemic therapy $y^{6,7}$. These options are determined not only by local control of the disease but also by organ functionality.

Considering that patient-related factors, such as nutritional and functional status, are directly related to lower cure rates ${ }^{8}$ and that early diagnosis has an important role in treatment outcome, this study aims at evaluating potential predictors of recurrence of laryngeal and laryngopharyngeal squamous cell carcinoma in patients subjected to organ preservation therapy (OPT), in order to support better follow-up of patients with laryngeal and laryngopharyngeal neoplasms.

\section{Methods}

\section{Sample}

This work aimed to evaluate whether patients with laryngopharyngeal and/or laryngeal squamous cell carcinoma who underwent OPT present, at the time of relapse, any factor that determines local relapse of the disease.

We selected patients submitted to OPT at the Instituto do Câncer do Estado de São Paulo (ICESP) with treatment ending between January 2012 and December 2017. The study has been approved by the institution's Research Ethics Committee under protocol number 228/14.

The study included retrospective data on demographic characteristics, clinical staging, primary tumor location, presence or absence of relapse, patient's weight and percentage of weight loss at different times (immediately before the start and after the end of treatment; at relapse or on last medical visit for those who did not relapse; three months before relapse or last visit for those who did not relapse), feeding route and symptomatology at the time of relapse or last visit for those who did not relapse (symptoms evaluated were: new pain complaint or worsening of previous pain pattern; worsening of eating pattern, dyspnea or dysphonia). 
The inclusion criterion was that the primary lesion should be squamous cell carcinoma restricted to the larynx and/or laryngopharynx. The exclusion criteria were evolution with local relapse, distant metastasis or second primary tumor; death before, during or immediately after treatment for the primary tumor; loss of follow-up; diagnosis of disease persistence (DP) less than three months after completion of primary lesion treatment; presence of primary tumor from another site or distant metastasis at initial presentation; need for total laryngectomy for a cause other than cancer rescue.

Data obtained by the study of each quantitative parametric distribution variable were treated and described using the mean and standard deviation. Absolute and relative frequencies were used for the qualitative analyses. Distributions were defined as parametric by the Kolmogorov-Smirnov test. Student's $t$ test was used to compare the means of two independent parametric sample populations. Chi-square or Fisher's exact tests were used to compare frequencies between groups. We used the SPSS ${ }^{\circledR} 24.0$ statistical software (SPSS ${ }^{\circledR}$ Inc; Illinois, USA) in all analyses, and adopted a level of statistical significance below $5 \%(p \leq 0.05)$ for all comparisons.

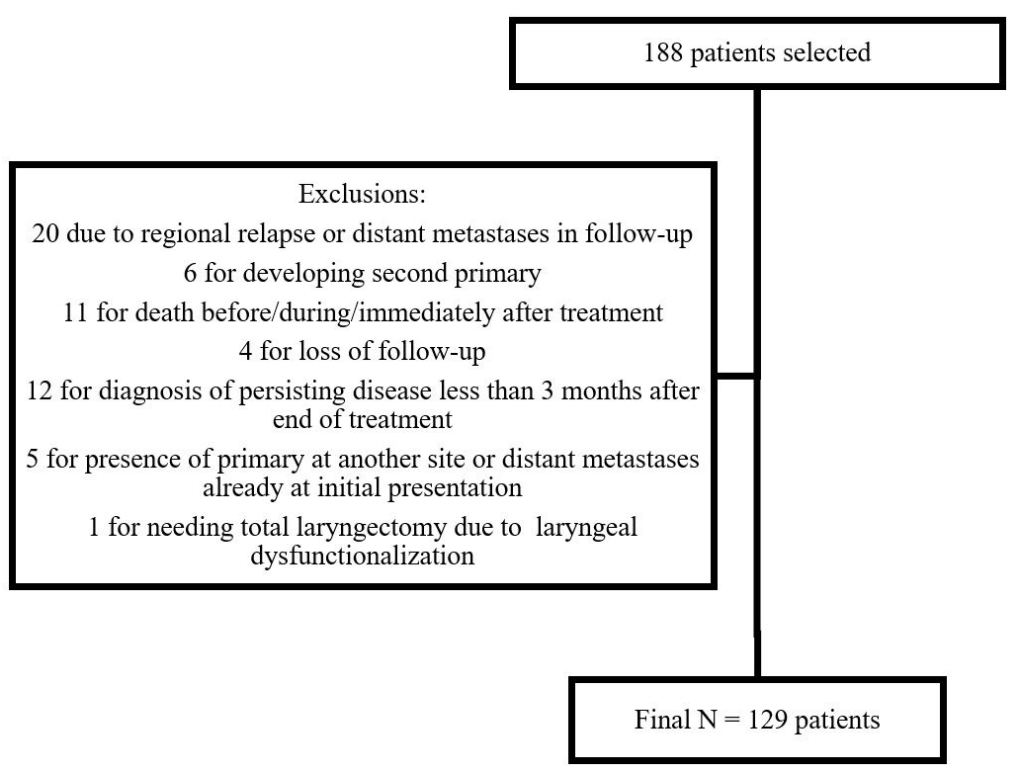

Figure 1. CONSORT diagram showing the selection of patients for the study.

\section{Results}

Initially, 188 patients were selected, as shown in Figure 1.

The average age of patients at the start of treatment for the primary tumor was 61.3 years of age, ranging from 40 to 87 years.

As for the location of the primary tumor, most patients had lesion in the glottis (36 cases), followed by transglottic tumors (Figure 2 ). 


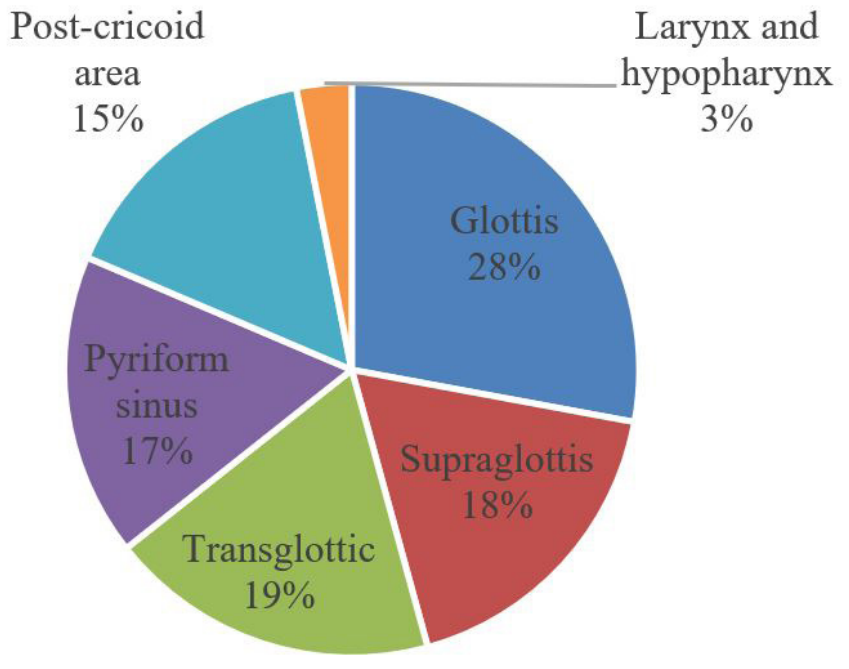

Figure 2. Distribution of cases according to primary tumor topography.

Table 1. Distribution of all cases by $T$ and $N$ clinical stage classifications.

\begin{tabular}{cccc}
\hline Tis & $0.8 \%$ & $\mathrm{~N} 0$ & $49.61 \%$ \\
\hline T1a & $8.7 \%$ & $\mathrm{~N} 1$ & $11.63 \%$ \\
\hline T1b & $7.9 \%$ & $\mathrm{~N} 2$ & $24.81 \%$ \\
\hline T2 & $13.5 \%$ & $\mathrm{~N} 3$ & $13.95 \%$ \\
\hline T3 & $24.6 \%$ & & \\
\hline T4a & $23.0 \%$ & & \\
\hline T4b & $21.4 \%$ & & \\
\hline
\end{tabular}

Patients were clinically classified according to the eighth edition of TNM, aided by direct laryngoscopy performed at the doctor's office and radiological examination by computed tomography or magnetic resonance imaging (Table 1).

Forty-nine of the patients evaluated (38\%) presented relapse or local DP, and 80 (62\%) did not relapse during follow-up. The mean time for relapse/DP was 1 year.

Most patients with no relapse presented the primary tumor in the glottis $(36,3 \%)$, predominantly with cT3 lesions; as for patients who relapsed, the majority presented transglottic lesions (22.4\%) at stage cT4 (Tables 2 and 3 ).

Regarding the group with no relapse, 66 patients (81.3\%) had no symptoms at the last consultation, whereas 14 patients (17.5\%) presented symptoms. Of the group with relapse/DP, eight patients (16.3\%) did not present symptoms at diagnosis, whereas 41 patients (83.7\%) presented symptoms. Absence of symptoms was associated with the absence of relapse ( $p<0,001$ - chi-square test) in this group of patients. The group of patients with symptoms was subdivided into five categories (Table 4). 
Table 2. Initial topography of primary tumor for the groups without relapse and with relapse.

\begin{tabular}{lcccccc} 
& Glottis & Supraglottic & Transglottic & $\begin{array}{c}\text { Pyriform } \\
\text { sinus }\end{array}$ & $\begin{array}{c}\text { Post-cricoid } \\
\text { area }\end{array}$ & $\begin{array}{c}\text { Larynx and } \\
\text { laryngopharynx }\end{array}$ \\
\hline Without relapse & $36.3 \%$ & $16.3 \%$ & $16.3 \%$ & $15 \%$ & $13.8 \%$ & $2.5 \%$ \\
\hline With relapse & $16.3 \%$ & $20.4 \%$ & $22.4 \%$ & $20.4 \%$ & $18.4 \%$ & $4.1 \%$ \\
\hline
\end{tabular}

Table 3. Initial T clinical staging of cases divided per group without relapse and with relapse.

\begin{tabular}{lccccccc} 
& Tis & T1 & T1b & T2 & T3 & T4a & T4b \\
\hline Without relapse & $1.3 \%$ & $13 \%$ & $10.4 \%$ & $14.3 \%$ & $30 \%$ & $18 \%$ & $13 \%$ \\
\hline With relapse & $0 \%$ & $2 \%$ & $4.1 \%$ & $12.2 \%$ & $16.4 \%$ & $30.6 \%$ & $34.7 \%$ \\
\hline
\end{tabular}

Table 4. Distribution of patients with symptoms in absolute numbers divided per group without relapse and with relapse.

\begin{tabular}{|c|c|c|c|c|c|}
\hline & $\begin{array}{c}\text { New pain } \\
\text { complaint/ } \\
\text { worsening of } \\
\text { previous pain } \\
\text { level }\end{array}$ & $\begin{array}{c}\text { Worsening of } \\
\text { nutritional } \\
\text { pattern }\end{array}$ & $\begin{array}{l}\text { Worsening of } \\
\text { dyspnea }\end{array}$ & $\begin{array}{l}\text { Worsening of } \\
\text { dysphonia }\end{array}$ & $\begin{array}{l}\text { Mixed (two } \\
\text { or more } \\
\text { symptoms) }\end{array}$ \\
\hline Without relapse & 3 & 4 & 2 & 3 & 1 \\
\hline With relapse & 22 & 8 & 3 & 1 & 7 \\
\hline
\end{tabular}

The patients' feeding route was assessed at the last consultation and classified as total oral nutrition, mixed or total enteral nutrition. In the comparison between patients without relapse and those with relapse/DP, oral nutrition was the main modality ( $81.3 \%$ vs. $55.1 \%)$, followed by total enteral nutrition $(16.3 \%$ vs. $34.7 \%)$ and mixed (2.5\% vs. $10.2 \%)$. The presence of total oral nutrition at the last consultation was a significantly important factor for the absence of relapse ( $p=0.005$ - chi-square test).

Weight comparison of all patients before starting organ preservation treatment and after the end of treatment showed an average drop of $3.4 \mathrm{~kg}$ (initial mean weight of $62.5 \mathrm{~kg}$ against final mean weight of $59.1 \mathrm{~kg}$ ). Sixty-seven percent of patients who presented relapse or DP lost weight after treatment; however, this condition was even more frequent in patients who were free of disease during follow-up (83.8\%) ( $p=0.030$ - chi-square test).

For the analysis of weight comparison at the time of relapse/last consultation with the consultation three months earlier, patients with total enteral diet were excluded, as this is a potential misleading variable in weight maintenance (Table 5).

In the analysis per group, the weight of patients who did not relapse at the last consultation was $63.4 \mathrm{~kg}$, while in their visit three months before the average was $63.7 \mathrm{~kg}$, which represents a mean loss of $0.7 \%$. As for those patients who presented relapse/DP, the mean weight at the time of relapse was of $55.8 \mathrm{~kg}$, while in their consultation three months before diagnosis, the average was 
Table 5. Comparison between weight and weight loss and relapse or local disease progression (DP) in outpatient assessments.

\begin{tabular}{|c|c|c|c|}
\hline Variable & $\begin{array}{l}\text { Absence of } \\
\text { relapse/DP* }\end{array}$ & $\begin{array}{l}\text { Presence of } \\
\text { relapse/DP* }\end{array}$ & p-Value** \\
\hline Weight immediately before start of treatment & $65.8 \pm 15.7 \mathrm{~kg}$ & $58.9 \pm 11.2$ & 0.201 \\
\hline Weight immediately after start of treatment & $62.0 \pm 13.9 \mathrm{~kg}$ & $57.7 \pm 11.7$ & 0.680 \\
\hline Percentage of weight loss after treatment & $-5.0 \pm-8.0 \%$ & $-1.4 \pm-13.3 \%$ & 0.214 \\
\hline $\begin{array}{l}\text { Weight three months before last consultation for those without } \\
\text { relapse or three months before relapse for those who relapsed }\end{array}$ & $63.5 \pm 14.5 \mathrm{~kg}$ & $58.7 \pm 11.2 \mathrm{~kg}$ & 0.554 \\
\hline $\begin{array}{l}\text { Percentage of weight loss three months before (considering } \\
\text { weight after treatment) }\end{array}$ & $2.6 \pm 10.7 \%$ & $2.3 \pm 9.1 \%$ & 0.187 \\
\hline $\begin{array}{l}\text { Weight at the last medical consultation for those without } \\
\text { relapse or at the moment of relapse for those who relapsed }\end{array}$ & $63.3 \pm 14.5 \mathrm{~kg}$ & $57.0 \pm 9.4 \mathrm{~kg}$ & 0.210 \\
\hline $\begin{array}{l}\text { Percentage of weight loss at relapse or at last consultation } \\
\text { (considering weight after treatment) }\end{array}$ & $2.2 \pm 11.2 \%$ & $0.1 \pm 11.8 \%$ & 0.930 \\
\hline $\begin{array}{l}\text { Percentage of weight loss at relapse or at last consultation } \\
\text { (considering weight } 3 \text { months before) }\end{array}$ & $-0.7 \pm 4.1 \%$ & $-2.06 \pm 9.1 \%$ & 0.005 \\
\hline
\end{tabular}

*Mean \pm standard deviation; **T-paired test; Note: "weight loss" with negative averages mean weight loss, and with positive averages, weight gain at observations.

$57.5 \mathrm{~kg}-\mathrm{a}$ loss of $2.0 \%$ of weight at the moment of relapse. The percentage of weight loss was significantly higher (2.1\%) at relapse as compared with their weight three months before diagnosis ( $p=0.005$ - Student's $t$ test).

\section{Discussion}

Laryngopharynx squamous cell carcinoma (SCC) presents one of the worst prognosis among head and neck neoplasms, although it has a better prognosis when located in the larynx, where it shows greater incidence. However, both present higher rates of diagnosis at advanced stages, which may reflect the scarcity of symptoms (in cases of laryngopharynx and sub/supraglot) as well as the difficulty of access to specialized health services. A retrospective study undertaken at a major Brazilian center in 2013 revealed a diagnostic rate of up to $94,7 \%{ }^{9}$ in cases of laryngopharyngeal squamous cell carcinoma stage III-IV. Six years later, the present study ratifies these findings showing a higher frequency of cases at the T3-T4a stages.

The treatment of larynx/laryngopharynx neoplasms rests on three pillars: surgery, chemotherapy and radiotherapy. The current trend in managing malignant larynx neoplasms is surgical treatment, particularly partial laryngectomies, for better local control of the disease and to reduce relapse rate. Although the last decades have seen great advancements, laryngopharynx still presents the higher rate of relapse and second primary among head and neck malignant neoplasms ${ }^{1}$. Bradley et al. ${ }^{10: 47-53}$ showed that delay over 14 months in beginning treatment corresponded consistently to a higher risk of death ${ }^{10}$. In the case of patients undergoing post-treatment follow-up (either surgical or chemotherapy/radiotherapy), evaluation and differentiation 
between recurrence, scarring, edema and local flaps by imaging can be challenging ${ }^{11}$.

Several recent studies have shown that most recurrences of head and neck malignant neoplasms are detected through symptoms reported by patients, instead of physical examination of asymptomatic patients during follow-up ${ }^{12}$. Boysen et al. ${ }^{12: 1-7}$ found "[...] a higher rate of symptomatic versus asymptomatic recurrences in glottic and supraglottic recurrences, particularly in the first two years of follow-up". This finding corroborates with our data, indicating that over $80 \%$ of patients with relapses had some complaint, and most asymptomatic patients were non-relapsed. This shows the importance of the patient being able to report new symptoms or changes in previous symptoms, and of the capacity of the medical team in alerting to the prospect of recurrence, aiming at early diagnosis to improve treatment and survival.

Weight loss is an important marker among patients with laryngeal and laryngopharyngeal squamous cell carcinoma, and an important criterion in choosing the treatment to be adopted. We showed that weight loss during post-treatment follow-up is also an important predictor of relapse, as patients without recurrence kept their weight practically constant during/between consultations, and those with confirmed recurrence presented a mean weight loss of $2 \%$ in the three months before diagnosis. The presence of symptoms should also serve as a warning during follow-up. We found a symptomatology rate above $80 \%$ among relapsed patients, while absence of symptoms prevailed among those with no recurrence. Thus, we have shown that both weight loss and the presence of symptoms during follow-up are extremely relevant factors in post-treatment care of these patients, as they signal the possibility of relapse of the squamous cell carcinoma and the need for earlier diagnostic investigation.

We know that guaranteeing a suitable feeding route-whether oral, enteral or via gastrostomy-for laryngeal and laryngopharyngeal squamous cell carcinoma patients is crucial for their care both pre- and post-treatment. However, data from the available literature recommend a "wait and see" approach regarding nutritional support, and so far benefits in introducing enteral diets or via gastrostomy prophylactically have not been shown ${ }^{13}$. It is up to the multidisciplinary medical team (surgeons, nutrologists, nutritionists and speech therapists) to decide on the introduction of complementary feeding routes, taking into consideration factors such as weight loss, incapacity for suitable oral feeding, risk of bronchoaspiration and those inherent to the passage of gastric tubes. In this study, we observed that total oral feeding was statistically associated with the absence of relapse, which is closely related to the natural progression of the disease in sites directly linked to the patient's swallowing capacity.

The present study aims at finding predictive factors for relapse of laryngeal and laryngopharyngeal squamous cell carcinoma after organ preservation therapy, in view of the technical and economic/administrative difficulties imposed to follow-up of these patients in a major referral center. Taking into account the small sample used in the study and the fact that weight loss, although relevant, proved to be small, we should use the data presented in a relative manner, adopting a case-by-case analysis to find the best course of action 
according to the peculiarities of each patient. However, as weight loss and the presence of symptoms have proven to be important and statistically relevant predictors of relapse, we believe we have contributed to the improvement of these patients management by means of earlier investigations, thus allowing for rescue treatments within a shorter period of time.

\section{References}

1. Bradley PJ. Symptoms and signs, staging and co-morbidity of hypopharyngeal cancer. Adv Otorhinolaryngol. 2019;83:15-26. http://dx.doi.org/10.1159/000492304. PMid:30943511.

2. Bradley P. Epidemiology of hypopharyngeal cancer. 2019. p. 1-14. http://dx.doi. org/10.1159/isbn.978-3-318-06389-9.

3. Lebo NL, Khalil D, Balram A, Holland M, Corsten M, Ted McDonald J, et al. Influence of socioeconomic status on stage at presentation of laryngeal cancer in the United States. Otolaryngol Head Neck Surg. 2019;161(5):0194599819856305. http://dx.doi.org/10.1177/0194599819856305. PMid:31184265.

4. Garneau JC, Bakst RL, Miles BA. Hypopharyngeal cancer: a state of the art review. Oral Oncol. 2018;86:244-50. http://dx.doi.org/10.1016/j. oraloncology.2018.09.025. PMid:30409307.

5. Kwon DI, Miles BA, Education Committee of the American Head and Neck Society (AHNS). Education Committee of the American Head and Neck S. Hypopharyngeal carcinoma: do you know your guidelines? Head Neck. 2019;41(3):569-76. http:// dx.doi.org/10.1002/hed.24752. PMid:30570183.

6. Patel SA, Qureshi MM, Dyer MA, Jalisi S, Grillone G, Truong MT. Comparing surgical and nonsurgical larynx-preserving treatments with total laryngectomy for locally advanced laryngeal cancer. Cancer. 2019;0(0):3367-77. http://dx.doi. org/10.1002/cncr.32292. PMid:31206637.

7. Aydil U, Akmansu M, Gümüşay Ö, Eravcı FC, Bakkal FK, Yazıcı Ö, et al. Failure of concurrent chemoradiotherapy for organ preservation in laryngeal cancer: survival outcomes and recurrence patterns. Ear Nose Throat J. 2019;98(7):0145561319839788. http://dx.doi.org/10.1177/0145561319839788. PMid:30983390.

8. Eckel HE, Bradley PJ. Future Perspectives in Hypopharyngeal Cancer Care. Adv Otorhinolaryngol. 2019;83:167-75. http://dx.doi.org/10.1159/000492361. PMid:30943472.

9. Amar A, Curioni OA, Paiva DL, Rapoport A, Dedivitis RA, Cernea CR, Brandão LG. Epidemiological assessment and therapeutic response in hypopharyngeal cancer. Rev Bras Otorrinolaringol (Engl Ed). 2013;79(4):500-4. http://dx.doi. org/10.5935/1808-8694.20130089. PMid:23929153.

10. Eckel HE, Bradley PJ. Treatment options for hypopharyngeal cancer. Adv Otorhinolaryngol. 2019;83:47-53. http://dx.doi.org/10.1159/000492308. PMid:30943512.

11. Piazza C, Paderno A, Ravanelli M, Pessina C. Clinical and Radiological Evaluation of Hypopharyngeal Carcinoma. Adv Otorhinolaryngol. 2019;83:35-46. http:// dx.doi.org/10.1159/000492306. PMid:30943514. 


\section{*Correspondence}

Sonyara Rauedys Lisboa

Universidade de São Paulo (USP),

Faculdade de Medicina (FM), Hospital das Clínicas, Disciplina de Cirurgia de Cabeça e Pescoço

Rua Dr. Enéas Carvalho de Aguiar, 201 CEP 05403-000, São Paulo (SP), Brasil Tel.: +55 (11) 94234-6154

E-mail: sonyaralisboa@gmail.com

\section{Authors information}

SRL, ACS, RGM and DAR - MD,

Department of Head and Neck Surgery, Medical School of the University of São Paulo - HCFMUSP. MGR - MD, Medical School of the University of São Paulo - HCFMUSP. DMR - MD, Department of Head and Neck Surgery, Medical School of the University of São Paulo HCFMUSP, Cancer Institute of São Paulo - ICESP. LLM and MAVK - MD, $\mathrm{PhD}$, Department of Head and Neck Surgery, Medical School of the University of São Paulo - HCFMUSP, Cancer Institute of São Paulo - ICESP.
12. Brandstorp-Boesen J, Zätterström U, Evensen JF, Boysen M. Value of patientreported symptoms in the follow up of patients potentially cured of laryngeal carcinoma. J Laryngol Otol. 2019;133(6):1-7. http://dx.doi.org/10.1017/ S0022215119000677. PMid:31006407.

13. Bozec A, Benezery K, Chamorey E, Ettaiche M, Vandersteen C, Dassonville O, Poissonnet G, Riss JC, Hannoun-Lévi JM, Chand ME, Leysalle A, Saada E, Sudaka A, Haudebourg J, Hebert C, Falewee MN, Demard F, Santini J, Peyrade F. Nutritional status and feeding-tube placement in patients with locally advanced hypopharyngeal cancer included in an induction chemotherapy-based larynx preservation program. Eur Arch Otorhinolaryngol. 2016;273(9):2681-7. http:// dx.doi.org/10.1007/s00405-015-3785-4. PMid:26395117. 